Article

\title{
Preparation and Characterization of Biomimetic Hydroxyapatite Nanocrystals by Using Partially Hydrolyzed Keratin as Template Agent
}

\author{
Chunxia Gao, Ke Zhao, Liwei Lin, Jinyu Wang, Yang Liu and Peizhi Zhu * \\ School of Chemistry and Chemical Engineering, Yangzhou University, Jiangsu 225009, China; \\ cxgao@yzu.edu.cn (C.G.); m160292@yzu.edu.cn (K.Z.); linlwei@sohu.com (L.L.); jinywang2@gmail.com (J.W.); \\ liuyangyzu@sohu.com (Y.L.) \\ * Correspondence: pzzhu@yzu.edu.cn
}

Received: 17 January 2019; Accepted: 30 January 2019; Published: 11 February 2019

\begin{abstract}
Hydroxyapatite (HA), a typical inorganic component of bone, is a widely utilized biomaterial for bone tissue repair and regeneration due to its excellent properties. Inspired by the recent findings on the important roles of protein in biomineralization and natural structure of fish scales, keratin was chosen as a template for modulating the assembly of HA nanocrystals. A series of HA nanocrystals with different sizes were synthesized by adjusting the concentration of partially hydrolyzed keratin. The structure and compositions of the prepared HA were characterized by Fourier transform infrared (FTIR) spectroscopy, X-ray diffraction (XRD), Raman spectrum, and Transmission electron microscopy (TEM). Results revealed that the size of the synthesized HA nanocrystals can be controlled by adjusting the concentration of partially hydrolyzed keratin. Specifically, the size of synthesized HA decreased from $63 \pm 1.5 \mathrm{~nm}$ to $27 \pm 0.9 \mathrm{~nm}$ with the increasing concentration of partially hydrolyzed keratin from 0 to $0.6 \mathrm{~g}$. In addition, in vitro cytocompatibility of synthesized HA nanocrystals were evaluated using the MG-63 cells.
\end{abstract}

Keywords: hydroxyapatite (HA); nanocrystal; hydrolyzed keratin; fish scales

\section{Introduction}

Hydroxyapatite (HA), with chemical composition $\mathrm{Ca}_{10}\left(\mathrm{PO}_{4}\right)_{6}(\mathrm{OH})_{2}$, has been increasingly used in clinical applications, such as orthopedics and dentistry, due to its similarity in crystal structures and compositions to biological apatite that can be found in hard tissues such as teeth and bones $[1,2]$. Various HA with different crystal structure and morphology have been developed [3]. Among these synthesized HA materials, nanostructured HA has received much attention due to their higher specific surface areas that enhance the adhesion of cells, proteins, and drugs [4]. In addition, inspired by the process of biomineralization of natural bones, various macromolecules have been chosen as a templating agent to manipulate the growth of HA crystals [5]. During the mineralization process of HA crystals, macromolecules can play the predominant role in the nucleation, growth, orientation, and structure of HA crystals [6]. Among these templating agents, proteins have received much attention due to their functional groups on side chains which can chelate $\mathrm{Ca}^{2+}$ ions and form hydrogen bonding with $\mathrm{PO}_{4}{ }^{3-}$ and $\mathrm{H}_{2} \mathrm{O}$ on the surface of the minerals $[7,8]$.

As one type of protein, keratins widely exist in biological systems, comprising the main component of natural materials such as hair, fur, wool, nails, hooves, and fish scales [9-14]. The helical molecular structure and macromolecular organization of $\alpha$-keratin impart these materials with notable characteristics such as strength and flexibility [15]. The fish scales are composed of calcium-deficient HA and extracellular matrix, mainly keratin, which together form a highly ordered three-dimensional 
hierarchical structure [16-18]. HA derived from the fish scale, have been considered as an ideal scaffold for the use in orthopedics since the minerals $\mathrm{Na}^{+}, \mathrm{Mg}^{2+}, \mathrm{F}^{-}, \mathrm{Cl}^{-}, \mathrm{K}^{+}$, and $\mathrm{CO}_{3}{ }^{2-}$ are present in HA derived from fish scale and make the apatites structurally similar to the apatites in a natural bone $[19,20]$. Keratin in fish scales act as one of the templates for the orientation of the mineral phase but how keratin regulates the morphology, size, and crystallinity of the apatite minerals in fish scales remains unknown [21-23]. Moreover, inspired by recent findings on the important roles of protein in biomineralization and natural structure of fish scales, we hypothesized that negatively charged segments of keratin could play an important role in regulating the mineralization process of HA crystals. To synthesize HA nanocrystals with controllable morphologies and sizes, keratin was chosen as a template. In the present study, partially hydrolyzed keratin was used due to the insolubility of keratin in an aqueous solution.

The main objective of this study was to investigate the effects of the concentration of partially hydrolyzed keratin on the morphology, size and biological activity of synthesized HA nanocrystals. The role of keratin on regulating the process of mineralization of HA crystals was investigated. Compositions, morphology and crystal structure of synthesized HA nanocrystals were also characterized. In addition, in vitro cytocompatibility of these synthesized HA nanocrystals was evaluated using human osteosarcoma cells (MG-63) regarding their proliferation.

\section{Materials and Methods}

\subsection{Materials}

The partially hydrolyzed keratin was purchased from Yuanchen Co., Ltd. (Wuhan, China). $\mathrm{Ca}\left(\mathrm{NO}_{3}\right)_{2} \cdot 4 \mathrm{H}_{2} \mathrm{O},\left(\mathrm{NH}_{4}\right)_{2} \mathrm{HPO}_{4}$ and ammonium hydroxide were purchased from Sinopharm Chemical Reagent Co., Ltd. (Beijing, China). All of the reagents were used as received without treatment or further purification.

\subsection{Preparation of HA Nanocrystals}

In this work, five groups of HA samples were synthesized, and the HA synthesized without keratin was design as S1 and HA derived from carp scale design as S6. S1 and S6 were set as the control groups. The formulae of all groups are shown in Table 1 . For HA synthesis, $\mathrm{Ca}\left(\mathrm{NO}_{3}\right)_{2} \cdot 4 \mathrm{H}_{2} \mathrm{O}$ and $\left(\mathrm{NH}_{4}\right)_{2} \mathrm{HPO}_{4}$ were chosen as the precursors of calcium and phosphorus source to synthesize HA by the co-precipitation method [24]. The partially hydrolyzed keratin served as soft templates for the synthesis of HA nanocrystals. Specifically, $9.54 \% \mathrm{Ca}\left(\mathrm{NO}_{3}\right)_{2} \cdot 4 \mathrm{H}_{2} \mathrm{O}$ was prepared and added a different concentration of partially hydrolyzed keratin $(0 \mathrm{~g}, 0.02 \mathrm{~g}, 0.1 \mathrm{~g}, 0.2 \mathrm{~g}$ and $0.6 \mathrm{~g}$ corresponding to S1, S2, S3, S4, and S5). To get the homogenous solution, the mixture stirred at $95^{\circ} \mathrm{C}$ for $2 \mathrm{~h}$. Then $3.2 \%\left(\mathrm{NH}_{4}\right)_{2} \mathrm{HPO}_{4}$ solution was dripped into the heated mixture solution, and $\mathrm{pH}$ value of the mixed solution was adjusted at 9.2 by the ammonium hydroxide solution. The suspension needed further $4 \mathrm{~h}$ stirring, and then aged at the room temperature for $24 \mathrm{~h}$. Finally, the obtained precipitate was washed by deionized water three times to remove partially hydrolyzed keratin and other soluble substances. Then, the samples were dried by lyophilization (Lyoquest- 55, Telstar, Barcelona, Spain). To prepare the control group, $20 \mathrm{~g}$ grass carp scales were dissolved in $100 \mathrm{~mL} 5 \mathrm{M} \mathrm{NaOH}$ solution under stirring for $4 \mathrm{~h}$ at $95^{\circ} \mathrm{C}$ [25]. Next, the insoluble precipitate was collected and washed by deionized water 3 times and dried by lyophilization 
Table 1. The formulae of synthesized HA samples (S1-S5) and HA derived from scales set as S6.

\begin{tabular}{cccc}
\hline Sample & $\mathbf{C a}\left(\mathbf{N O}_{\mathbf{3}} \mathbf{~}_{\mathbf{2}} \cdot \mathbf{4} \mathbf{H}_{\mathbf{2}} \mathbf{O}\right.$ & $\mathbf{( N H}_{\mathbf{4}} \mathbf{~} \mathbf{2}_{\mathbf{2}} \mathbf{H P O}_{\mathbf{4}}$ & Partially Hydrolyzed Keratin \\
\hline $\mathrm{S} 1$ & $9.54 \mathrm{~g}$ & $3.20 \mathrm{~g}$ & - \\
$\mathrm{S} 2$ & $9.54 \mathrm{~g}$ & $3.20 \mathrm{~g}$ & $0.02 \mathrm{~g}$ \\
$\mathrm{~S} 3$ & $9.54 \mathrm{~g}$ & $3.20 \mathrm{~g}$ & $0.1 \mathrm{~g}$ \\
$\mathrm{~S} 4$ & $9.54 \mathrm{~g}$ & $3.20 \mathrm{~g}$ & $0.2 \mathrm{~g}$ \\
$\mathrm{~S} 5$ & $9.54 \mathrm{~g}$ & $3.20 \mathrm{~g}$ & $0.6 \mathrm{~g}$ \\
$\mathrm{~S} 6$ & - & - & - \\
\hline
\end{tabular}

\subsection{Characterization of HA Nanocrystals}

The size and morphology of obtained HA nanoparticles were characterized by transmission electron microscopy (TEM, Tecnai C2 F30 S-Twin, FEI, Hillsboro, OR, USA). Wide-angle X-ray diffraction (XRD, $X^{\prime}$ pert-MPD, Philips, Amsterdam, The Netherlands) was used to determine the presence of crystalline phases in these synthesized samples. The XRD analysis was performed using $\mathrm{Ni}$-filtered $\mathrm{CuK} \alpha$ radiation $(\lambda=1.5402 \AA)$ in a step-scan mode ( $2^{\circ}$ per minute) in the $2 \theta$ range $10-60^{\circ}$. Composition analysis of the prepared scaffolds was performed using Fourier transform infrared (FT-IR) spectroscopy (ALPHA, BRUKER, Karlsruhe, Germany). FT-IR was performed in the wave-number range of 400-4000 $\mathrm{cm}^{-1}$, each FTIR spectrum was obtained from 40 scans at a resolution of $2 \mathrm{~cm}^{-1}$. The molecular structure was further analyzed by Raman spectroscopy (DXR, GX-PT-2412, Thermo, Waltham, MA, USA) with $532 \mathrm{~nm}$ laser as excitation wavelength.

\subsection{In Vitro Cytocompatibility}

In vitro cytocompatibility of the prepared samples was evaluated using a Human osteosarcoma cell line MG-63 cells, obtained from the Stem Cell Bank, Chinese Academy of Sciences (Shanghai, China). Prior to seeding with cells, the samples $(50 \mu \mathrm{g} / \mathrm{mL})$ were sterilized using ethylene oxide gas and then placed in 96-well culture plates. MG-63 cells were seeded onto samples with a density of 5000 cells/well $(\mathrm{n}=3)$. Alpha-modified minimum essential medium with L-Glutamine and Phenol Red ( $\alpha$-MEM, Gibco, Grand Island, NY, USA), supplemented with $10 \%$ heat-inactivated fetal bovine serum (FBS, GibcoTM, Invitrogen, Grand Island, NY, USA) was used as the culturing medium. A Thermanox ${ }^{\circledR}$ culture plastic plate (TCP) was used as the control group. The cultures were incubated at $37{ }^{\circ} \mathrm{C}$ in a humidified atmosphere of $95 \%$ air and $5 \% \mathrm{CO}_{2}$, with the medium changed every 2 days. After the incubation for predetermined days, cell viability was assessed by Live/Dead staining assay and cell proliferation assay. The tests were repeated 3 times for each cement formulation $(n=3)$. The LIVE/DEAD ${ }^{\circledR}$ Viability/Cytotoxicity Kit (Thermo Fisher Scientific, L-3224, Waltham, MA, USA) was used according to the manufacturer's instructions. Briefly, after the cell culture medium was removed, $100 \mu \mathrm{L}$ of PBS containing $4 \mu \mathrm{M}$ calcein-AM and $2 \mu \mathrm{M}$ ethidium homodimer- 1 was added to stain live and dead cells, respectively. After incubating for $10 \mathrm{~min}$ at $37^{\circ} \mathrm{C}$, cells were then examined via epifluorescence microscopy (Olympus ix53, Hataya, Japan). For each sample, five images were taken.

After incubation for 1, 3 and 5 days, cell proliferation was examined using Cell Counting Kit- 8 (CCK-8, Dojindo, Kumamoto, Japan), in accordance with the manufacturer's instruction. Briefly, samples were removed after each incubation, rinsed two times with PBS and added $100 \mu \mathrm{L}$ PBS. Then, $10 \mu \mathrm{L}$ of CCK-8 reagent was added to each sample and cultured in an incubator at $37^{\circ} \mathrm{C}$ with $5 \%$ $\mathrm{CO}_{2}$ for an additional $2 \mathrm{~h}$. After $2 \mathrm{~h}$ incubation, $100 \mu \mathrm{L}$ of media were transferred to each well of a 96-well plate to measure absorption value at a wavelength of $450 \mathrm{~nm}$ using a microplate reader (Elx-800, bio-Tek instruments, Winooski, VT, USA).

\subsection{Statistical Analysis}

The numeric data were expressed as mean \pm standard deviation (SD) and analyzed using one-way analysis of variance (ANOVA). 


\section{Results and Discussion}

XRD patterns of nature HA derived from fish scales and synthesized HA by using partially hydrolyzed keratin as a template is shown in Figure 1. The diffraction peaks appeared in these synthesized HA agree with those of the standard HA (JCPDS No. 09-0432) [7,8], which indicated that the HA crystals have been successfully synthesized. According to the Figure 1, peaks observed at $2 \theta$ degree of $26.1,32.1,33.0,40.1,47.0,49.7$ and 53.4 can be recognized to (002), (211), (300), (310), (222), (213) and (004) reflections of HA [26,27]. Broader peaks and lower peak resolution of HA (S6) from the fish scales indicate lower crystallinity and smaller size of HA nanocrystals than those of synthetic HA samples [28,29]. The XRD patterns of partially hydrolyzed keratin (S7) is also shown in Figure 1. The peak at $2 \theta$ degree of about 19 means the keratin used in this study is the $\beta$-sheet crystalline structure [30].

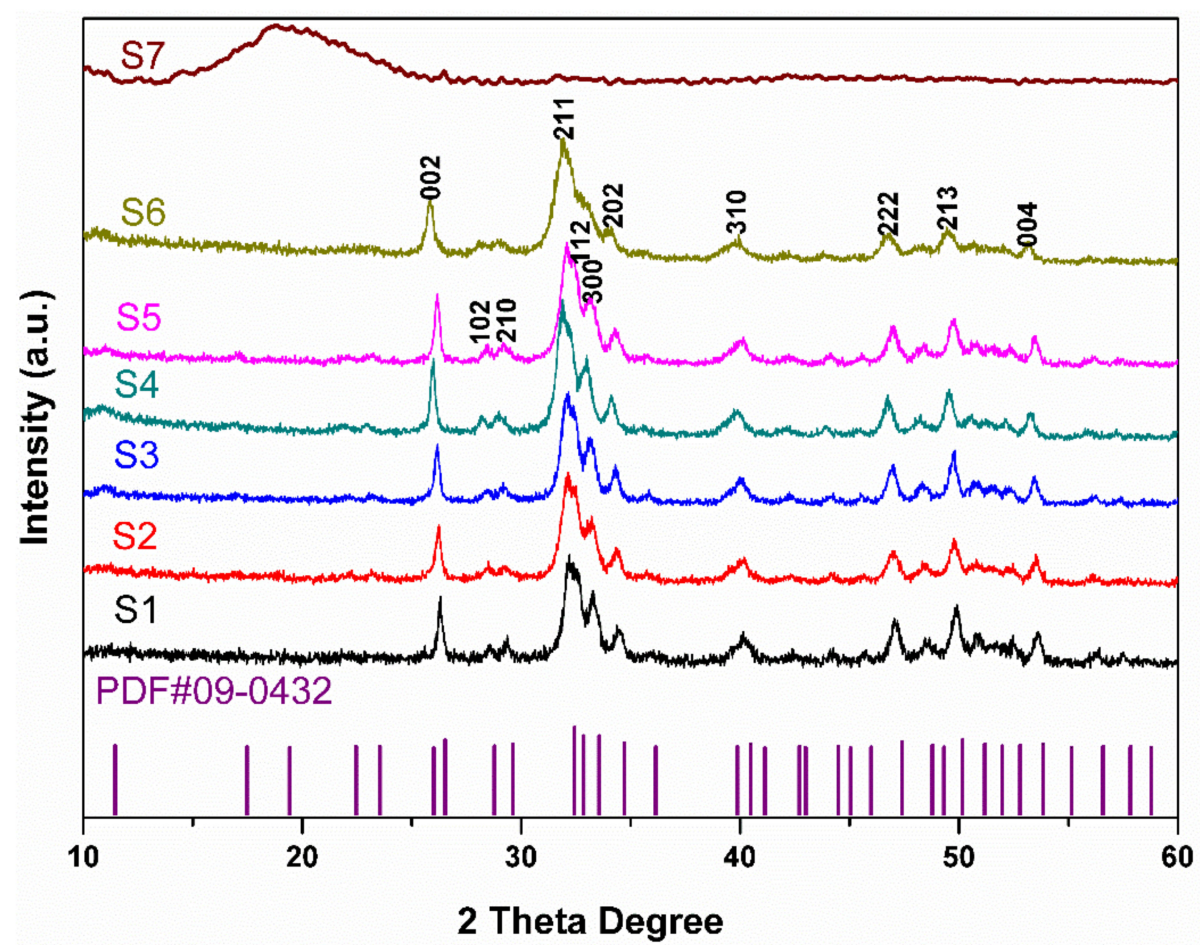

Figure 1. XRD patterns of synthesized HA samples (S1-S5), HA derived from carp scales (S6) and partially hydrolyzed keratin (S7).

The FTIR spectra of nature HA derived from fish scales and synthesized HA by using partially hydrolyzed keratin as a template are shown in Figure 2. The absorption peaks at 1089, 1024 and $962 \mathrm{~cm}^{-1}$ can be attributed to $v 1$ and $v 3$ phosphate modes. The absorption peaks at 560 and $600 \mathrm{~cm}^{-1}$ are attributed to $v 4$ phosphate modes [31]. The peaks at 630 and $3569 \mathrm{~cm}^{-1}$ from S1 should be assigned to hydroxyl groups $\left(\mathrm{OH}^{-}\right)$[32]. With the increasing concentration of partially hydrolyzed keratin, the intensity of these two peaks becomes weak. We can hardly find $\mathrm{OH}$ signal at $3569 \mathrm{~cm}^{-1}$ from HA (S6) derived from fish scales. The antisymmetric stretching vibration of $\mathrm{C}-\mathrm{O}(\mathrm{v} 3)$ in the region of $1500-1400 \mathrm{~cm}^{-1}$ and $v 2$ vibration of $\mathrm{CO}_{3}{ }^{2-}$ at $875 \mathrm{~cm}^{-1}$ indicate that $\mathrm{HA}$ (S6) derived from fish scales contains $\mathrm{CO}_{3}{ }^{2-}$. S7 is the FTIR spectra of partially hydrolyzed keratin, the main peaks at 1515 and $1645 \mathrm{~cm}^{-1}$ are the peak of amino-group $(\mathrm{N}-\mathrm{H})$ and amide bond $(\mathrm{CO}-\mathrm{NH})$, respectively. Raman spectra of all HA samples are also shown in Figure 2. The characteristic peaks of $\mathrm{PO}_{4}{ }^{3-}$ at 420 and $578 \mathrm{~cm}^{-1}$ can be assigned to $v 2$ and $v 4$ mode, respectively [33]. The peaks at $1037 \mathrm{~cm}^{-1}$ are corresponding to antisymmetrical stretching vibrations (v3) of $\mathrm{PO}_{4}{ }^{3-}$ ion and peaks at $1070 \mathrm{~cm}^{-1}$ can be attributed to $\mathrm{CO}_{3}{ }^{2-}$ ions in HA crystal lattice [34,35]. The strongest symmetric stretch $v 1$ mode of $\mathrm{PO}_{4}{ }^{3-}$ is situated at $956 \mathrm{~cm}^{-1}$ and the $\mathrm{O}-\mathrm{H}$ stretch can be found at $\sim 3567 \mathrm{~cm}^{-1}$ [31]. All HA samples have an OH signal 
at $3567 \mathrm{~cm}^{-1}$. However, the weak intensity of $\mathrm{OH}$ peak and strong signal of $\mathrm{CO}_{3}{ }^{2-}$ ions at $1070 \mathrm{~cm}^{-1}$ of HA (S6) derived from the fish scale is much lower than those of synthetic HA samples because some $\mathrm{OH}$ ions in apatite lattice have been substitute by $\mathrm{CO}_{3}{ }^{2-}$ ions.

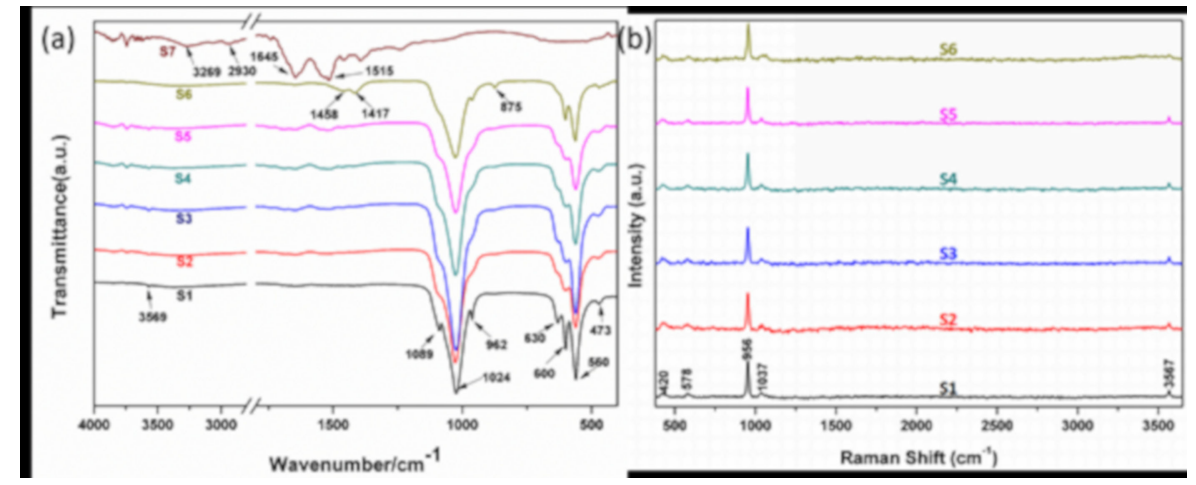

Figure 2. FTIR spectra (a) of synthesized HA samples (S1-S5), HA derived from grass carp scales and partially hydrolyzed keratin (S7) and Raman spectra (b) of synthesized HA samples (S1-S5) and HA derived from grass carp scales.

In our previous study, we found the size of HA can be affected by the molecular weight of chitosan oligosaccharide [8]. However, the morphology and size are difficult to control under $\sim 100 \mathrm{~nm}$. Thus, inspired by recent findings on important roles of protein in biomineralization and natural structure of fish scales, we hypothesized that negatively charged segments of keratin could play an important role in regulating the mineralization process of HA crystals. TEM was used to characterize the morphology and size of synthesized and natural derived HA samples. Figure 3a shows that the length of synthesized HA nanocrystals without adding hydrolyzed keratin (S1) is about $63 \pm 1.5 \mathrm{~nm}$. With the increase of hydrolyzed keratin concentration, the length of HA nanocrystals decreased (Figure $3 \mathrm{~b}-\mathrm{e}$ ). The average length of S2, S3, S4, S5, and S6 is $58 \pm 1.8 \mathrm{~nm}, 52 \pm 1.5 \mathrm{~nm}, 38 \pm 1.1 \mathrm{~nm}$, $27 \pm 0.9 \mathrm{~nm}$ and $20 \pm 3.4 \mathrm{~nm}$, respectively, indicating that the negatively charged segments on side chains of keratin play a key role in regulating the morphology and size of HA nanocrystals [36]. As previously known, partially hydrolyzed keratin contains many amino groups $\left(-\mathrm{NH}_{2}\right)$, carboxyl groups $(-\mathrm{COOH})$, mercapto groups $(-\mathrm{SH})$ and even sulfonic groups $\left(-\mathrm{OSO}_{3} \mathrm{H}\right)$ and $\mathrm{Ca}^{2+}$ ions can bond with these functional groups. When the concentration of partially hydrolyzed keratin increases, the content of free $\mathrm{Ca}^{2+}$ in solution becomes lower, which causes the slower formation rate of HA crystals, eventually leading to the formation of smaller crystals [37]. Figure $3 \mathrm{f}$ shows that natural HA (S6) has an irregular shape and much smaller size than the other samples, which could be attributed to low crystallinity due to the high carbonate content. The selected area electron diffraction (SEAD) patterns show multi-crystalline electron diffraction concentrate rings attributed to (002), (102) and (211) crystallographic planes of HA [38]. In accordance with XRD and FTIR results, the size slightly decreased with the increased concentration of partially hydrolyzed keratin. The changes in the size of the nanocrystals were noticeable when $0.2 \mathrm{~g}$ of the partially hydrolyzed keratin was used. With the content of partially hydrolyzed keratin up to $0.6 \mathrm{~g}$, the size of the nanocrystals ranged from $63 \pm 1.5 \mathrm{~nm}$ to $27 \pm 0.9 \mathrm{~nm}$. According to the results, the size of HA nanocrystals gradually decreased from about $63 \pm 1.5 \mathrm{~nm}$ to $27 \pm 0.9 \mathrm{~nm}$ as the content of partially hydrolyzed keratin increased from 0 to $0.6 \mathrm{~g}$. Therefore, a new strategy for the synthesis of HA nanocrystals with controllable sizes by using partially hydrolyzed keratin as a templating agent was developed. In our opinion, the size and shape of the HA can influence their applications. Nanosized HA can be used as carriers of the drug, protein, and gene delivery due to their large surface area, improved sinterability and better bioactivity [39]. Hannig and Hannig also found these nano-sized apatite enamel crystallites may promote remineralization and physiological biofilm management of the tooth surface [40].

It is well known that synthetic HA is a bioactive material that is chemically similar to the mineral component of a bone. Indeed, the human bone is a natural composite comprising of nano-apatite rods 
(which are, $100 \mathrm{~nm}$ ) arranged in lamellae and bound to collagen. Thus, synthetic nano-apatite is of interest as a biocompatible phase reinforcement in biomedical composites, for filling bulk bone defects and for coatings on metal implants [41]. Moreover, HA and other calcium phosphates (calcium deficient hydroxyapatite, CDHA) are also of interest as components in injectable bone cement; controlling particle properties (e.g., size and shape) is often used to modulate cement setting behavior. In this study, we chose the HA derived from carp scales as the control due to the following reasons. Firstly, HA from fish bone and scales has emerged as an alternative to substituting the synthetic and bovine HA in the last years since similar chemical properties have been achieved by simple and inexpensive methods [42]. Secondly, it has been demonstrated that fish sources are safe and present low risks of disease transmission [43]. Thirdly, fish are abundant in the environment, and the application of their byproducts is suitable for biomedical application as it would reduce environmental pollution and threats of biohazards to humans.

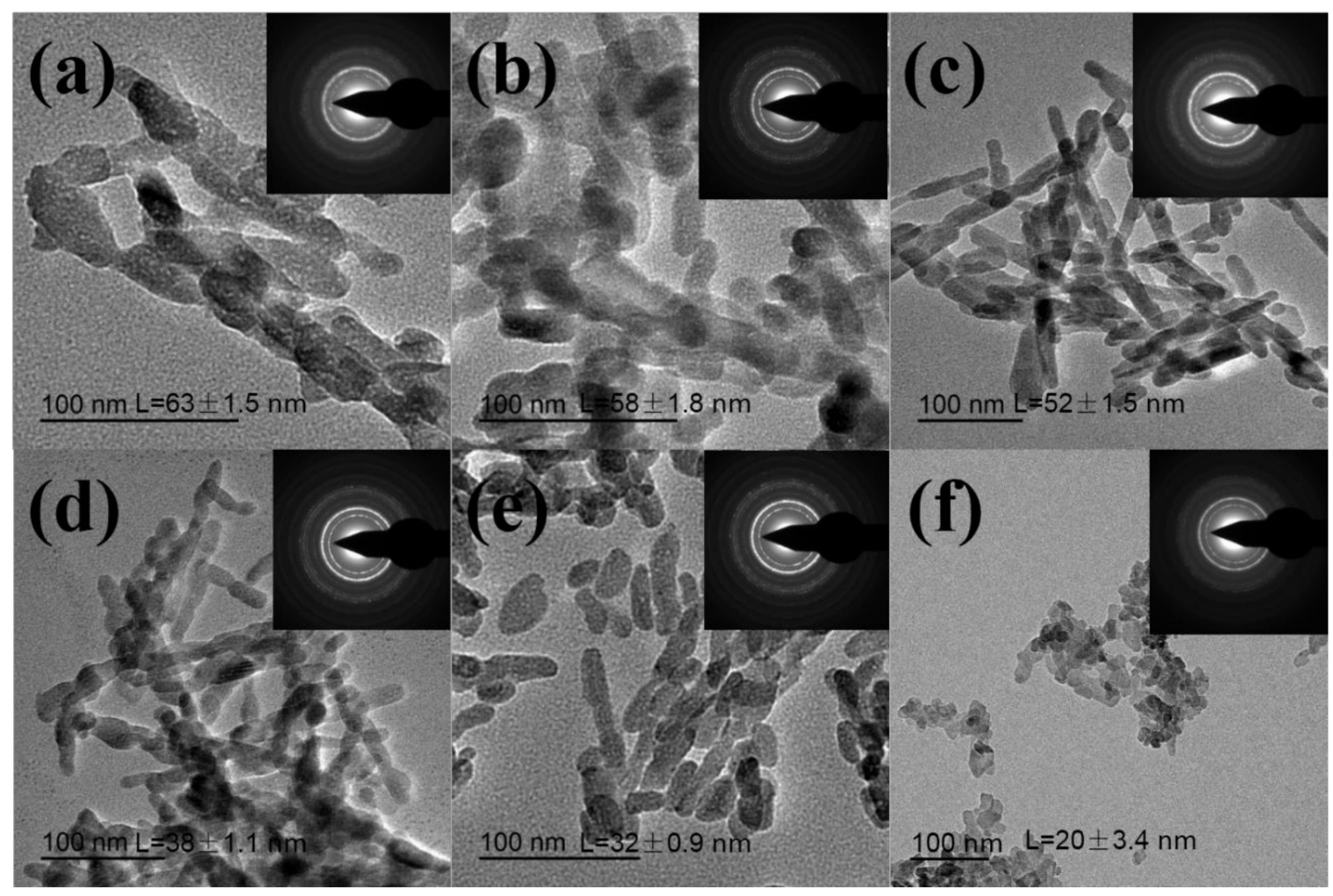

Figure 3. TEM and SEAD images of synthesized HA samples: (a-e) S1-S5 and HA derived from grass carp scales (f) S6.

In vitro cytocompatibility of synthesized and naturally derived HA was investigated using CCK-8 assay and Live/Dead fluoresce staining of MG-63 cell line. Proliferation results of MG-63 cells cultured in the HA samples for 1, 3 and 5 days are shown in Figure 4. Cell proliferation of all groups was similar, while there were obvious increases in the cell numbers after 3 and 5 days. This finding indicated that that MG-63 cells grew regularly on all synthesized HA nanocrystals. Further, it was clearly observed that all syntheses exhibited similar cell proliferation to the $\alpha$-MEM control which indicated all synthesized HA nanocrystals have excellent cytocompatibility. The viability of MG-63 cells cultured in HA samples was also evaluated by Live/Dead staining after culturing for 1 and 3 days, as shown in Figure 5. Figure 5 also showed that the numbers of live cells increased on all samples after 3 days and the cells on all synthesized and $\alpha$-MEM control proliferated to a confluence with very few dead cells. These results demonstrated that all synthesized HA nanocrystals have no cytotoxicity. 


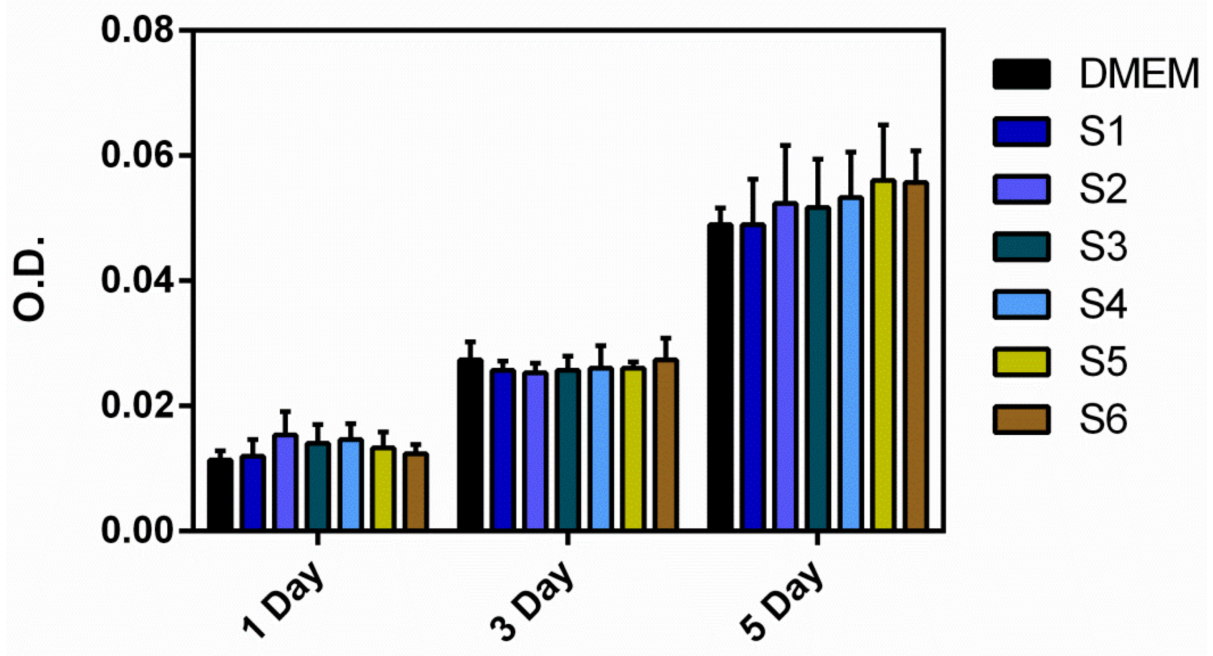

Culture Time

Figure 4. In vitro cytotoxicity of MG-63 cell lines after culturing in the synthesized HA samples (S1-S5) and HA derived from carp scales (S6) and DMEM for 1, 3 and 5 days.
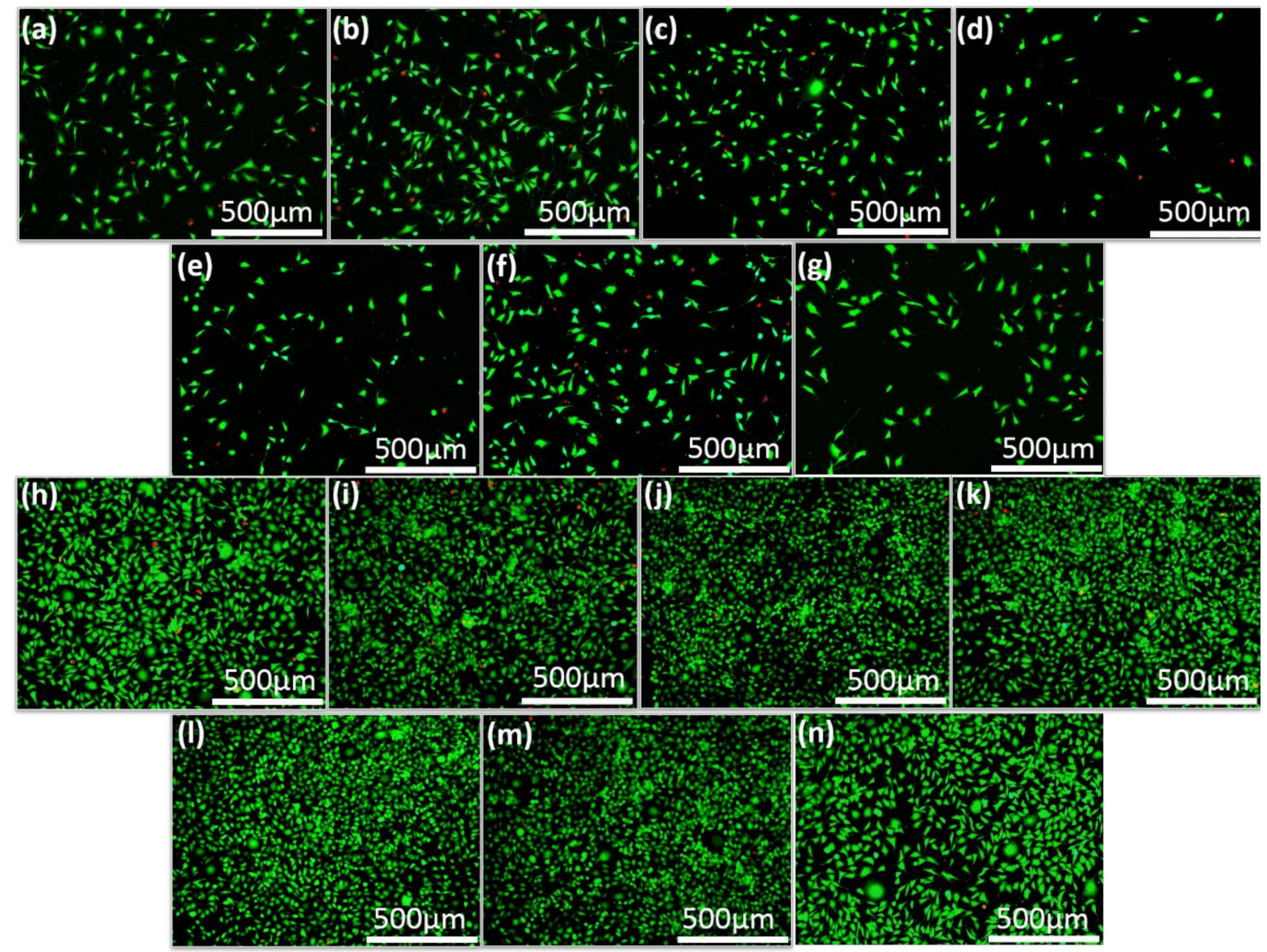

Figure 5. Live/Dead staining of MG-63 cells after cultured in HA samples and DMEM for 1 day (a-g) and 3 days $(\mathbf{h}-\mathbf{n}) .(\mathbf{a}-\mathbf{g}),(\mathbf{h}-\mathbf{n})$ are S1-S6 samples and (g), (n) DMEM which acted as the control group.

\section{Conclusions}

In the present study, a new strategy for synthesizing of HA nanocrystals with controllable sizes was developed by using partially hydrolyzed keratin as the templating agent. Results revealed that grain-like morphology of HA nanocrystals was obtained in the presence of partially hydrolyzed 
keratin. The concentration of partially hydrolyzed keratin in the process of the HA synthesis process influenced the HA crystal size. As the content of partially hydrolyzed keratin increased from 0 to $0.6 \mathrm{~g}$, the size of HA nanocrystals gradually decreased from about $63 \pm 1.5 \mathrm{~nm}$ to $27 \pm 0.9 \mathrm{~nm}$, which get close to crystal morphologies of natural apatites derived from fish scales. Results suggested that the partially hydrolyzed keratin play a positive role in the nucleation and growth of HA nanocrystals. In vitro, cytocompatibility assays showed that these synthesized HA nanocrystals enhanced MG-63 proliferation up to 5 days compared to natural derived HA. All these results indicated that prepared HA nanoparticles could be promising candidates for bone tissue engineering applications.

Author Contributions: P.Z. and C.G. conceived and designed the experiments. K.Z. and L.L. performed synthetic experiments. J.W. and Y.L. contributed materials of experiments and analysis tools. P.Z., C.G., and K.Z. analyzed the data and wrote the final manuscript. All authors read and approved the final manuscript.

Funding: This research was funded by the Technology Support Program of Science and Technology Department of Jiangsu Province (BE2017689), Technology Support Program of Science and Technology Department of Yangzhou City (YZ2018084), and the National Natural Science Foundation of China (81601880).

Conflicts of Interest: The authors declare that they have no conflict of interest.

\section{References}

1. Cölfen, H. Biomineralization: A crystal-clear view. Nat. Mater. 2010, 9, 960-961. [CrossRef] [PubMed]

2. Finnemore, A.; Cunha, P.; Shean, T.; Vignolini, S.; Guldin, S.; Oyen, M.; Steiner, U. Biomimetic layer-by-layer assembly of artificial nacre. Nat. Commun. 2012, 3, 966. [CrossRef] [PubMed]

3. Fihri, A.; Len, C.; Varma, R.S.; Solhy, A. Hydroxyapatite: A review of syntheses, structure and applications in heterogeneous catalysis. Coord. Chem. Rev. 2017, 347, 48-76. [CrossRef]

4. Zhou, H.; Lee, J. Nanoscale hydroxyapatite particles for bone tissue engineering. Acta Biomater. 2011, 7 , 2769-2781. [CrossRef] [PubMed]

5. Bera, T.; Ramachandrarao, P. Morphological changes in biomimetically synthesized hydroxyapatite and silver nanoparticles for medical applications. J. Mater. Sci. 2009, 44, 2264-2270. [CrossRef]

6. Wang, Y.; Azaïs, T.; Robin, M.; Vallée, A.; Catania, C.; Legriel, P.; Pehau-Arnaudet, G.; Babonneau, F.; Giraud-Guille, M.-M.; Nassif, N. The predominant role of collagen in the nucleation, growth, structure and orientation of bone apatite. Nat. Mater. 2012, 11, 724. [CrossRef] [PubMed]

7. Deng, Y.; Sun, Y.; Chen, X.; Zhu, P.; Wei, S. Biomimetic synthesis and biocompatibility evaluation of carbonated apatites template-mediated by heparin. Mater. Sci. Eng. C Mater. Biol. Appl. 2013, 33, $2905-2913$. [CrossRef]

8. Wang, J.; Liu, G.; Chen, J.; Zhao, B.; Zhu, P. Synthesis of biocompatible hydroxyapatite using chitosan oligosaccharide as a template. Materials 2015, 8, 8097-8105. [CrossRef]

9. Campinho, M.A.; Silva, N.; Sweeney, G.E.; Power, D.M. Molecular, cellular and histological changes in skin from a larval to an adult phenotype during bony fish metamorphosis. Cell Tissue Res. 2007, 327, 267-284. [CrossRef]

10. Sharma, S.; Gupta, A.; Kumar, A.; Kee, C.G.; Kamyab, H.; Saufi, S.M. An efficient conversion of waste feather keratin into ecofriendly bioplastic film. Clean Technol. Environ. Policy 2018, 20, 2157-2167. [CrossRef]

11. Vasilevich, F.I.; Bobyleva, O.V.; Sapozhnikova, A.I.; Gordiyenko, I.M.; Gorbacheva, M.V. Products recycling waste fur production: New capabilities to use. Res. J. Pharm. Biol. Chem. Sci. 2018, 9, 1590.

12. Okazaki, M.; Yoshimura, K.; Fujiwara, H.; Suzuki, Y.; Harii, K. Induction of hard keratin expression in non-nail-matrical keratinocytes by nail-matrical fibroblasts through epithelial-mesenchymal interactions. Plast. Reconstr. Surg. 2003, 111, 286-290. [CrossRef] [PubMed]

13. Kakkar, P.; Madhan, B.; Shanmugam, G. Extraction and characterization of keratin from bovine hoof: A potential material for biomedical applications. Springerplus 2014, 3, 596. [CrossRef] [PubMed]

14. Leichner, C.; Steinbring, C.; Baus, R.A.; Baecker, D.; Gust, R.; Bernkop-Schnurch, A. Reactive keratin derivatives: A promising strategy for covalent binding to hair. J. Colloid Interface Sci. 2019, 534, 533-541. [CrossRef] [PubMed]

15. Chen, B.B.; Xing, Y.; Yu, W.D.; Liu, H.L. Wool keratin and silk sericin composite films reinforced by molecular network reconstruction. J. Mater. Sci. 2018, 53, 5418-5428. [CrossRef] 
16. Bigi, A.; Burghammer, M.; Falconi, R.; Koch, M.H.J.; Panzavolta, S.; Riekel, C. Twisted plywood pattern of collagen fibrils in teleost scales: An x-ray diffraction investigation. J. Struct. Biol. 2001, 136, 137-143. [CrossRef] [PubMed]

17. Ferraro, V.; Anton, M.; Santé-Lhoutellier, V. The "sisters" $\alpha$-helices of collagen, elastin and keratin recovered from animal by-products: Functionality, bioactivity and trends of application. Trends Food Sci. Technol. 2016, 51, 65-75. [CrossRef]

18. Ikoma, T.; Kobayashi, H.; Tanaka, J.; Walsh, D.; Mann, S. Microstructure, mechanical, and biomimetic properties of fish scales from Pagrus major. J. Struct. Biol. 2003, 142, 327-333. [CrossRef]

19. Mondal, B.; Mondal, S.; Mondal, A.; Mandal, N. Fish scale derived hydroxyapatite scaffold for bone tissue engineering. Mater. Charact. 2016, 121, 112-124. [CrossRef]

20. Pon-On, W.; Suntornsaratoon, P.; Charoenphandhu, N.; Thongbunchoo, J.; Krishnamra, N.; Tang, I.M. Synthesis and investigations of mineral ions-loaded apatite from fish scale and PLA/chitosan composite for bone scaffolds. Mater. Lett. 2018, 221, 143-146. [CrossRef]

21. Chen, S.; Ikoma, T.; Ogawa, N.; Migita, S.; Kobayashi, H.; Hanagata, N. In vitro formation and thermal transition of novel hybrid fibrils from type I fish scale collagen and type I porcine collagen. Sci. Technol. Adv. Mater. 2010, 11, 035001. [CrossRef]

22. Takagi, Y.; Ura, K. Teleost fish scales: A unique biological model for the fabrication of materials for corneal stroma regeneration. J. Nanosci. Nanotechnol. 2007, 7, 757-762. [CrossRef] [PubMed]

23. Youn, H.S.; Shin, T.J. Supramolecular assembly of collagen fibrils into collagen fiber in fish scales of red seabream, Pagrus major. J. Struct. Biol. 2009, 168, 332-336. [CrossRef]

24. Zhang, C.; Xu, H.; Geng, X.; Wang, J.; Xiao, J.; Zhu, P. Effect of spray distance on microstructure and tribological performance of suspension plasma-sprayed hydroxyapatite-titania composite coatings. J. Thermal Spray Technol. 2016, 25, 1255-1263. [CrossRef]

25. Granito, R.N.; Muniz Renno, A.C.; Yamamura, H.; de Almeida, M.C.; Menin Ruiz, P.L.; Ribeiro, D.A. Hydroxyapatite from fish for bone tissue engineering: A promising approach. Int. J. Mol. Cell. Med. 2018, 7 , 80-90. [CrossRef] [PubMed]

26. Balas, F.; Pérez-Pariente, J.; Vallet-Regí, M. In vitro bioactivity of silicon-substituted hydroxyapatites. J. Biomed. Mater. Res. Part A 2010, 66, 364-375.

27. Wang, J.; Xue, C.; Zhu, P. Hydrothermal synthesis and structure characterization of flower-like self assembly of silicon-doped hydroxyapatite. Mater. Lett. 2017, 196, 400-402. [CrossRef]

28. Suchanek, W.L.; Byrappa, K.; Shuk, P.; Riman, R.E.; Janas, V.F.; TenHuisen, K.S. Preparation of magnesium-substituted hydroxyapatite powders by the mechanochemical-hydrothermal method. Biomaterials 2004, 25, 4647-4657. [CrossRef]

29. Silva, C.C.; Graça, M.P.F.; Valente, M.A.; Góes, J.C.; Sombra, A.S.B. Microwave preparation, structure and electrical properties of calcium-sodium-phosphate biosystem. J. Non-Cryst. Solids 2006, 352, 3512-3517. [CrossRef]

30. Choi, J.; Panthi, G.; Liu, Y.; Kim, J.; Chae, S.-H.; Lee, C.; Park, M.; Kim, H.-Y. Keratin/poly (vinyl alcohol) blended nanofibers with high optical transmittance. Polymer 2015, 58, 146-152. [CrossRef]

31. Xue, C.; Chen, Y.; Huang, Y.; Zhu, P. Hydrothermal synthesis and biocompatibility study of highly crystalline carbonated hydroxyapatite nanorods. Nanoscale Res. Lett. 2015, 10, 316. [CrossRef] [PubMed]

32. Sun, R.-X.; Lv, Y.; Niu, Y.-R.; Zhao, X.-H.; Cao, D.-S.; Tang, J.; Sun, X.-C.; Chen, K.-Z. Physicochemical and biological properties of bovine-derived porous hydroxyapatite/collagen composite and its hydroxyapatite powders. Ceram. Int. 2017, 43, 16792-16798. [CrossRef]

33. Antonakos, A.; Liarokapis, E.; Leventouri, T. Micro-Raman and FTIR studies of synthetic and natural apatites. Biomaterials 2007, 28, 3043-3054. [CrossRef] [PubMed]

34. Anjaneyulu, U.; Pattanayak, D.K.; Vijayalakshmi, U. Snail shell derived natural hydroxyapatite: Effects on NIH-3T3 cells for orthopedic applications. Adv. Manuf. Process. 2016, 31, 206-216. [CrossRef]

35. Yamini, D.; Devanand, V.G.; Kumar, J.; Ramakrishnan, V. Raman scattering studies on PEG functionalized hydroxyapatite nanoparticles. Spectrochim. Acta Part A Mol. Biomol. Spectrosc. 2014, 117, 299-303. [CrossRef] [PubMed]

36. Teng, S.; Shi, J.; Peng, B.; Chen, L. The effect of alginate addition on the structure and morphology of hydroxyapatite/gelatin nanocomposites. Compos. Sci. Technol. 2006, 66, 1532-1538. [CrossRef] 
37. Fang, W.; Zhang, H.; Yin, J.; Yang, B.; Zhang, Y.; Li, J.; Yao, F. Hydroxyapatite crystal formation in the presence of polysaccharide. Cryst. Growth Des. 2016, 16, 1247-1255. [CrossRef]

38. Geng, Z.; Yuan, Q.; Zhuo, X.; Li, Z.; Cui, Z.; Zhu, S.; Liang, Y.; Liu, Y.; Bao, H.; Li, X. Synthesis, characterization, and biological evaluation of nanostructured hydroxyapatite with different dimensions. Nanomaterials 2017, 7, 38. [CrossRef]

39. Okada, M.; Furuzono, T. Hydroxylapatite nanoparticles: Fabrication methods and medical applications. Sci. Technol. Adv. Mater. 2012, 13, 5233-5240. [CrossRef]

40. Hannig, C.; Hannig, M. Natural enamel wear-A physiological source of hydroxylapatite nanoparticles for biofilm management and tooth repair? Med. Hypotheses 2010, 74, 670-672. [CrossRef]

41. Chaudhry, A.A.; Haque, S.; Kellici, S.; Boldrin, P.; Rehman, I.; Khalid, F.A.; Darr, J.A. Instant nano-hydroxyapatite: A continuous and rapid hydrothermal synthesis. Chem. Commun. 2006, 21, 2286-2288. [CrossRef] [PubMed]

42. Venkatesan, J.; Pallela, R.; Bhatnagar, I.; Kim, S.K. Chitosan-amylopectin/hydroxyapatite and chitosan-chondroitin sulphate/hydroxyapatite composite scaffolds for bone tissue engineering. Int. J. Biol. Macromol. 2012, 51, 1033-1042. [CrossRef] [PubMed]

43. Hoyer, B.; Bernhardt, A.; Heinemann, S.; Stachel, I.; Meyer, M.; Gelinsky, M. Biomimetically mineralized salmon collagen scaffolds for application in bone tissue engineering. Biomacromolecules 2012, 13, 1059-1066. [CrossRef] [PubMed]

(C) 2019 by the authors. Licensee MDPI, Basel, Switzerland. This article is an open access article distributed under the terms and conditions of the Creative Commons Attribution (CC BY) license (http:// creativecommons.org/licenses/by/4.0/). 